\title{
Best Practice Diabetes Injection Technique is Key to Improved Glycaemic Variability and Avoiding Injection Site Issues
}

\section{Kenneth Strauss}

Global Medical Director, BD Diabetes Care, POB 13, Erembodegem, Belgium

*Corresponding author: Kenneth Strauss, Global Medical Director, BD Diabetes Care, POB 13, Erembodegem - Drop 86, B - 9320, Erembodegem, Belgium, Tel: +32.53.720.465; E-mail: kenneth_strauss@europe.bd.com

Rec date: Oct 27, 2014 Acc date: Feb 19, 2015 Pub date: Feb 26, 2015

Copyright: @ 2015 Strauss K. This is an open-access article distributed under the terms of the Creative Commons Attribution License, which permits unrestricted use, distribution, and reproduction in any medium, provided the original author and source are credited.

\section{Commentary}

Diabetes is now a top public health challenge, with, according to the World Health Organization and International Diabetes Federation, the world "facing a growing diabetes epidemic of potentially devastating proportions" [1,2]. In 2013, it was recorded that 382 million people in the world have diabetes and this figure is set to rise to 592 million by 2035 [3]

In addition, the number of people with type 2 diabetes is increasing in nearly every country (IDF, 2013) and as people are diagnosed at an earlier age, yet are living longer, there is an increasing likelihood that they will need to use injectable therapies to control their condition [4].

It is well established that improving glycaemic control reduces the risk of developing long term complications. In the longer term, poor glycaemic control can increase the risk of complications including kidney failure, blindness and limb amputation, all of which have a devastating impact for the individual [5].

Correct injection technique is crucial for injectable therapies to achieve optimal glycaemic control. A common problem associated with poor injection technique is lipohypertrophy ( $\mathrm{LH})$. $\mathrm{LH}$ is an anabolic process involving fat tissue at the sites of insulin injections. Such sites develop textural changes often described as "rubbery" in the subcutaneous layer, often associated with repeatedly injecting into the same area. It has been estimated that about half of people with diabetes will experience $\mathrm{LH}$ at some time in their life. Injecting into areas of $\mathrm{LH}$ can result in variable absorption and erratic glycaemic control. A recent study by Blanco et al., has confirmed that incorrect site rotation and needle re-use are the two main causative factors [6].

\section{The Blanco Study}

The objective of the study was to assess the frequency of LH and its relationship to site rotation, needle re-use, glucose variability, hypoglycaemia and use of insulin. The study included 430 outpatients with diabetes treated in primary care (PC) as well as at specialty centres $(\mathrm{SpC})$ in the region of Andalusia, the community of Valencia, and the autonomous cities of Ceuta and Melilla in Spain. Patients were recruited randomly according to the order in which they were seen in the clinic. Study personnel had no knowledge of the LH status of patients at study entry. The patients, who were all insulin users, completed a wide-ranging questionnaire regarding their injection technique before their injection sites were examined by a diabetes nurse for the presence of $\mathrm{LH}$.

The results showed that nearly two-thirds (64.4\%) of patients had $\mathrm{LH}$. There was a strong relationship between the presence of $\mathrm{LH}$ and non-rotation of sites, with correct rotation technique having the strongest protective value against LH. Of the patients who correctly rotated sites, only $5 \%$ had $\mathrm{LH}$ while, of the patients with $\mathrm{LH}, 98 \%$ either did not rotate sites or rotated incorrectly [7]. Also, $39.1 \%$ of patients with LH had unexplained hypoglycaemia and $49.1 \%$ had glycaemic variability compared with only $5.9 \%$ and $6.5 \%$, respectively, in those without LH. LH was also related to needle reuse, with risk increasing significantly when needles were used more than five times.

\section{Guidance on Lipohypertrophy}

It is therefore evident that medical professionals have a duty of care to teach patients best practice injection technique in order to ensure they do not inject into Lipohypertrophic tissue and help them prevent the formation of LH in the first place. Providing good advice at the initiation of an injectable therapy is key, but it is often at a later stage that problems related to poor injection technique arise, so regular review and re-education where necessary with patients is important. A key aspect of this should be the monitoring of injection sites for $\mathrm{LH}$.

Detection of LH requires both visual inspection and palpation of injection sites as some lesions are more easily felt than seen. It is important to teach patients how to examine themselves for $\mathrm{LH}$, in the same way a healthcare professional might advise self-examination to detect signs of breast or testicular cancer. Patients need to be aware of LH and its potential impact on their glycaemic control, as well as how to prevent it, recognize it, and, if it develops, how to help the area to recover. Patients should look for any lumps, swelling, or redness and pay attention to the feel of any irregularities or hardening of the skin.

An experienced healthcare professional can teach patients how to identify LH through visual inspection as well as palpation. Problems such as LH tend to develop gradually and the individual may be unaware of the problem. Healthcare workers should encourage a patient to adopt systematic site rotation as this can help to reduce the risk of developing $\mathrm{LH}$.

Where LH is detected, the individual should be advised not to inject into the site until the tissue returns to normal, which may take many months. Abnormalities should be documented and sites monitored at every subsequent review. It is important to be wary when switching from injecting into areas of $\mathrm{LH}$ (where insulin is likely to be poorly absorbed) to normal tissue. The improved, quicker insulin absorption may require a reduction in dose. How much a dose should be reduced by will depend on the individual and should be guided by frequent blood glucose testing.

The Blanco et al. study found that people with LH use more insulin because the growth of the tissue acts as a barrier. Patients consuming an average of 15 units in less than a day in the absence of $\mathrm{LH}$, which, 
for a health care system such as that Spanish, can lead to a saving, both for patients and for the operators of $€ 122 \mathrm{M}$ [8].

\section{Injection Technique}

It is important to re-visit injection technique as a whole and examine injection sites as part of routine, on-going management. Healthcare professionals should reassess how people with diabetes are delivering their injectable therapy in the same way that inhaler technique is reviewed when monitoring people with asthma or chronic obstructive pulmonary disease. No matter how efficacious a therapy is, if it is not administered properly it will have suboptimal effect.

When instructing patients on injection technique, caregivers should choose a quiet place to be able to respond calmly to all the questions that are asked, such as those relating to the fear of the pain of the injection, the difficulties in the workplace, or other issues. It is essential to put the person at ease, showing all that is needed for proper administration, as the subject in their own homes will have to act independently and safely.

Although the key focus of this article is on LH and how to avoid its formation, it is important to also outline guidance on overall injection technique best practice as this plays a very important part in ensuring optimum glycaemic control. Incorrect technique can include: the use of an inappropriate needle length, failure to rotate injection sites correctly and the re-use of needles. As well as LH, the mismanagement of such factors can lead to injectable therapies being absorbed in an unpredictable manner. This can cause immediate problems such ashypoglycaemia (if insulin is injected into muscle where it is absorbed more quickly), hyperglycaemia (if it is injected into damaged tissue where it will be poorly absorbed), and perhaps even ketoacidosis in those with Type 1 diabetes.

The recent AMD-OSDI consensus of recommendations on the correct injection technique for diabetes patients states the following: "The reasons for the failure to achieve optimal glycaemic control depends on many factors, including the modality of administration, storage and handling of the insulin which plays an important role in the care pathway. Therefore, one of the goals of the physician team must be to ensure the attainment of the necessary knowledge and skills that lead to the proper use of hypoglycaemic injective drugs, in the proper use of injection devices and the correct application of injection techniques by patients with diabetes and their care givers in order to make full use of all the therapeutic potentials" [9].

\section{Needle Length}

The recommended site for insulin injections is the subcutaneous layer, the layer of fat immediately below the skin. Injecting into the subcutaneous layer allows the insulin to be absorbed at a more predictable rate, which can result in better glycaemic control. It is essential to assess each person individually when advising on correct needle length. Skin thickness is on average $2 \mathrm{~mm}$ regardless of gender, age, BMI, or ethnicity [10]. However, subcutaneous depth can vary from person to person according to BMI and gender, but also from site to site. For example, in a person with android obesity, the depth of the subcutaneous layer may be as little as $2-4 \mathrm{~mm}$ on the legs and arms, but $20-30 \mathrm{~mm}$ at the abdomen. There is a misconception that people with greater subcutaneous tissue depth, particularly overweight and obese people, require a longer needle. In fact, it makes no difference whether agents are injected shallowly or deeply into the subcutaneous tissue; they will be absorbed at a similar rate.
When only longer needles were available, the only option for those with little subcutaneous depth was to use a lifted skin fold or an angled injection to avoid an intramuscular injection. The availability of shorter needles $(4 \mathrm{~mm})$ however, has meant that individuals can inject at a $90^{\circ}$ angle without a lifted skin fold. However, even injecting at $90^{\circ}$ without pinch, the use of a short needle reduces the risk of injecting into the muscle, without increasing the reflux insulin. The use of a 4 $\mathrm{mm}$ needle is suitable for adult patients on insulin therapy, regardless of BMI as well as to children and adolescents (Figure 1) [11,12].

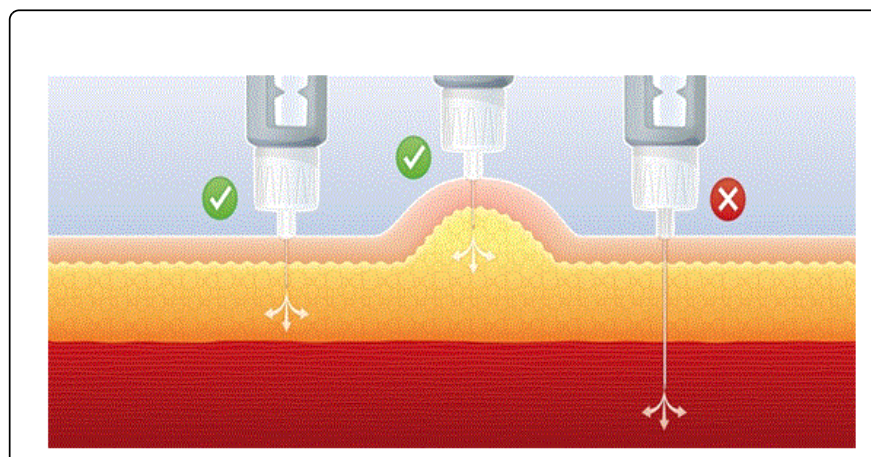

Figure 1: Injection depth with short $(4 \mathrm{~mm})$ vs longer pen needles

Systematic site rotation helps to reduce the risk of developing LH. An effective injection site rotation scheme involves identifying the injection areas (abdomen, thighs, buttocks and arms) and using each injection zone for up to one week, following a rotation guide moving always in the same direction, either clockwise or anti-clockwise. Injections within any zone should be spaced at least one centimetre apart from each other to avoid repeat tissue trauma (Figure 2) [13,14].

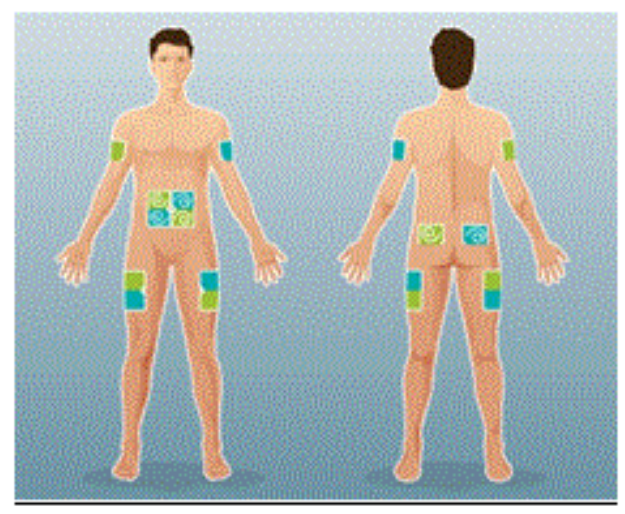

Figure 2: Recommended Injection Sites and Site Rotation

\section{Conclusion}

The Blanco et al. study highlights the importance of proper injection technique to achieve optimal glycemic control and in order to avoid risk factors of $\mathrm{LH}$ in insulin-injecting patients with diabetes. It also demonstrates that health professionals play a key role in ensuring that patients with diabetes are delivering their injectable therapy in the correct way so to avoid glycemic variability and its negative consequences. 
Citation: Strauss K (2015) Best Practice Diabetes Injection Technique is Key to Improved Glycaemic Variability and Avoiding Injection Site Issues. General Med 3: 1000168. doi:10.4172/2327-5146.1000168

Page 3 of 3

\section{References}

1. WHO, The World Health Report, 2004.

2. IDF Diabetes Atlas Sixth Edition, 2013.

3. Ibid (2013)

4. Ibid (2014).

5. Kanavos P, van den Aardweg S, Schurer W (2012) Diabetes expenditure, burden of disease and management in $5 \mathrm{EU}$ countries. LSE.

6. Blanco M, Hernández MT, Strauss KW, Amaya M (2013) Prevalence and risk factors of lipohypertrophy in insulin- injecting patients with diabetes, Diabetes Metab. 39: 445-453.

7. Strauss K, De Gols H, Hannet I, Partanen TM, Frid A (2002) A panEuropean epidemiologic study of insulin injection technique in patients with diabetes. Practical Diabetes International 19: 71-76.

8. Blanco M, Hernández MT, Strauss KW, Amaya M (2013) Prevalence and risk factors of lipohypertrophy in insulin- injecting patients with diabetes, Diabetes Metab. 39: 445-453.

9. Consensus AMD-OSDI sulle Tecnicheiniettivenelsoggetto diabetic (2014) A cura del Gruppo Inter-Societario AMD-OSDI sulleTecnicheiniettive; Il Giornale di AMD 17: 176-181
10. Gibney MA, Arce CH, Byron KJ, Hirsch LJ (2010) Skin and subcutaneous adipose layer thickness in adults with diabetes at sites used for insulin injections: implications for needle length recommendations. Curr Med Res Opin 26: 1519-1530.

11. Birkebaek N, Solvig J, Hanson B, et al., (2008) A 4 mm needle reduces the risk of intramuscular injections without increasing backflow to skin surface in lean diabetic children and adults. Diabetes Care 31: e65.

12. Laurence J Hirsch, Michael A. Gibney, John Albanese, Shangkang Qu, Kenneth Kassler-Taub, et al. (2010) Comparative glycemic control, safety and patient ratings for a new $4 \mathrm{~mm} \times 32 \mathrm{G}$ insulin pen needle in adults with diabetes. Current Medical Research \& Opinion 26: 1531-1541.

13. Lo Presti D, Ingegnosi C, Strauss K (2012) Skin and subcutaneous thickness at injecting sites in children with diabetes: ultrasound findings and injecting recommendations. Pediatr Diabetes 13: 525-533

14. Hirsch LJ, Gibney MA, Albanese J, Qu S, Kassler-Taub K, et al. (2010) Comparative glycemic control, safety and patient ratings for a new $4 \mathrm{~mm} \mathrm{x}$ 32G insulin pen needle in adults with diabetes. Curr Med Res Opin 26: 1531-1541. 